\title{
Sulfur oxidation of Paracoccus pantotrophus: the sulfur-binding protein SoxYZ is the target of the periplasmic thiol-disulfide oxidoreductase SoxS
}

Correspondence

Cornelius G. Friedrich

cornelius.friedrich@udo.edu

Received 25 March 2008

Revised 24 April 2008

Accepted 25 April 2008
Dagmar Rother, Josefina Ringk and Cornelius G. Friedrich

\author{
Lehrstuhl für Technische Mikrobiologie, Fakultät Bio- und Chemieingenieurwesen, Technische \\ Universität Dortmund, D-44221 Dortmund, Germany
}

\section{INTRODUCTION}

The proteins that reconstitute the sulfur-oxidizing (Sox) enzyme system in vitro from the Gram-negative, neutrophilic, facultatively aerobic and facultatively chemolithoautotrophic thiosulfate-oxidizing alpha-proteobacteria Paracoccus versutus and Paracoccus pantotrophus have been characterized (reviewed by Kelly et al., 1997; Friedrich et al., 2005).

Four periplasmic proteins, SoxYZ, SoxB, SoxCD and SoxXA, reconstitute the Sox enzyme system in vitro, which oxidizes hydrogen sulfide, sulfur, thiosulfate and sulfite, and transfers the electrons to horse cytochrome $c$. The heterodimeric haem enzyme SoxXA binds the sulfur substrate and covalently links it to the thiol of the single cysteine110 residue of the SoxY subunit (10977 Da) (Bamford et al., 2002). With SoxZ (11719 Da), SoxY forms the metal- and cofactorless SoxYZ complex. With sulfide as substrate, SoxY-cysteine persulfide is formed. The outer (sulfane) sulfur atom is oxidized by sulfane dehydrogenase SoxCD (formerly designated sulfur dehydrogenase) to sulfone, yielding SoxY-cysteine-S-sulfate. SoxCD is an $\alpha 2 \beta 2$ tetramer of the molybdoprotein SoxC

Abbreviations: Sox, sulfur oxidation; ssDNA, single-stranded DNA.
(43897 Da) and the dihaem cytochrome $c$ SoxD (38 $899 \mathrm{Da})$. Finally, SoxY-cysteine-S-sulfate is hydrolysed by the dimanganese SoxB protein $(58611 \mathrm{Da})$ to yield sulfate and to regenerate SoxY for a new reaction cycle of SoxYZ (Friedrich et al., 2001, 2005).

The SoxYZ complex is redox-active, very likely via the carboxy-terminal Cys- $110^{\mathrm{Y}}$, which is exposed and solventaccessible, as is evident from its crystal structure (Sauvé et al., 2007). Cys-110 $\mathrm{Y}$ accidentally forms interprotein disulfides to yield e.g. SoxY-Y $(\mathrm{Z})_{2}$ (Quentmeier et al., 2007). This heterotetramer is catalytically inactive (A. Quentmeier, unpublished data), and the reduction of the interprotein disulfide would reactivate the SoxYZ complex.

The Sox proteins that catalyse sulfur oxidation in vitro are encoded by seven genes. However, the sox gene region of $P$. pantotrophus comprises 15 genes, soxRSVWXYZA-H, which are organized in three transciptional units (Rother et al., 2001). The soxSR genes encode the respective proteins and are transcribed divergently to soxVWXYZA-H with soxR being located downstream of soxS. SoxR, a repressor of the ArsR family, binds to two intergenic regions of the soxVWXYZA-H cluster (Rother et al., 2005). The mature SoxS (99 aa, $11077 \mathrm{Da}$ ) is a periplasmic thiol-disulfide oxidoreductase 
and is essential for chemotrophic growth with thiosulfate, as is evident from the homogenote mutant $P$. pantotrophus $\mathrm{GB} \Omega S$. SoxS is not required for sulfur oxidation in vitro, as the Sox system of cell-free extracts of strain GB $\Omega S$ has identical activity to that of the wild-type. Genetic complementation of strain $\mathrm{GB} \Omega S$ demonstrates that SoxS activates the Sox enzyme system in vivo. SoxS is not involved in the expression of the sox genes (Orawski et al., 2007).

Thioredoxins act as antioxidants of other proteins by cysteine thiol-disulfide exchange. In the cytoplasm of Escherichia coli, two thiol redox systems exist: the thioredoxin and the glutaredoxin systems. Both prevent disulfide stress by reducing disulfide-bonded cytosolic proteins. The thioredoxins are reduced by respective reductases, which receive their electrons from NADPH. Glutaredoxin is reduced by glutathione oxidoreductase with glutathione as the source of electrons (reviewed by Ritz \& Beckwith, 2002; Linke \& Jakob, 2003). In the periplasm, thioredoxins or more specific thiol-disulfide oxidoreductases are reduced by membrane proteins, which deliver reductants via cysteine thiol-disulfide transporters. One such transporter is the DsbA/DsbB system, which plays a vital role in posttranslational modifications in the folding, stability and activity of many secreted proteins (reviewed by Kadokura et al., 2003; Nakamoto \& Bardwell, 2004). Other systems, such as CcdA, are required for cytochrome $c$ biogenesis (ThönyMeyer, 1997; Bardischewsky \& Friedrich, 2001a).

Interaction between a thiol-disulfide oxidoreductase and its redox partner has been demonstrated for the proteindisulfide-forming DsbA and its periplasmic partners by sitedirected mutagenesis (Kishigami et al., 1995). In the DsbA/ DsbB system, DsbA oxidizes substrate cysteines to proteindisulfide, and the membrane-bound DsbB protein reoxidizes DsbA (Tapley et al., 2007). One cysteine residue of the thiol-disulfide oxidoreductase CysXaaXaaCys motif interacts with a protein-disulfide and the other one reduces an intermediate state, which covalently links the thiol-disulfide oxidoreductase with its partner protein. Therefore, mutagenesis of each cysteine residue of SoxS, Cys- $13^{\mathrm{S}}$ and Cys- $16^{\mathrm{S}}$ will trap and identify the periplasmic partner of SoxS.

The cysteine-disulfide transporter SoxV of P. pantotrophus is a paralogue of CcdA and transfers electrons from the cytoplasm to the periplasm. SoxV is essential and specific for thiosulfate oxidation in vivo and is not involved in cytochrome $c$ biogenesis or heavy metal resistance. Moreover, SoxV reduces the thioredoxin SoxW and very likely also SoxS. However, SoxW, in contrast to SoxS, is not essential for chemotrophic growth (Bardischewsky et al., 2006; Orawski et al., 2007).

The essentiality of SoxS for chemotrophic sulfur oxidation in vivo raises the question of the identity of its reaction partner. Here, we describe cysteine residue exchanges in the thioredoxin motif of SoxS and the SoxZ subunit of the SoxYZ complex, and their phenotypes for sulfur oxidation. The immunochemical and protein biochemical analyses identified the sulfur-binding protein SoxY as the redox partner of SoxS.

\section{METHODS}

Bacterial strains and plasmids. Strains and plasmids used and constructed in this study are listed in Table 1.

Media and growth conditions. E. coli were cultivated in LuriaBertani (LB) medium (Sambrook et al., 1989) at $37^{\circ} \mathrm{C}$. Strains of $P$. pantotrophus (Rainey et al., 1999; Ludwig et al., 1993; Robertson \& Kuenen, 1983) were cultivated mixotrophically in mineral medium, $\mathrm{pH} 7.2$, with $20 \mathrm{mM}$ thiosulfate plus $20 \mathrm{mM}$ disodium succinate at $30{ }^{\circ} \mathrm{C}$ (Bardischewsky \& Friedrich, 2001b) or heterotrophically in mineral medium, $\mathrm{pH} 6.8$, with $20 \mathrm{mM}$ disodium succinate at $30{ }^{\circ} \mathrm{C}$. Antibiotics were added where appropriate (for E. coli $100 \mu \mathrm{g}$ ampicillin $\mathrm{ml}^{-1}, \quad 25 \mu \mathrm{g}$ chloramphemicol $\mathrm{ml}^{-1}, 50 \mu \mathrm{g}$ kanamycin $\mathrm{ml}^{-1}$ or $15 \mu \mathrm{g}$ tetracycline $\mathrm{ml}^{-1}$, and for P. pantotrophus $300 \mu \mathrm{g}$ kanamycin $\mathrm{ml}^{-1}$ and $5 \mu \mathrm{g}$ tetracycline $\mathrm{ml}^{-1}$ ).

DNA and gene transfer techniques. Standard DNA techniques were applied (Sambrook et al., 1989). Plasmid DNA was isolated according to Kieser (1984). Restriction enzymes and T4 DNA ligase were obtained from Promega or Roche and used as recommended by the manufacturers. Single-stranded DNA (ssDNA) was produced with plasmid pRD175.2, a derivative of vector pGEM-11ZF + (Promega) using the helper phage R408 (Promega) according to the instructions of the supplier. The amino acid exchanges in SoxS and SoxZ were performed with the GeneEditor in vitro site-directed mutagenesis system from Promega. For DNA sequencing (Sanger et al., 1977), plasmid DNA was prepared with the Wizard Plus SV Miniprep kit (Promega). DNA was sequenced as described previously (Rother et al., 2001). DNA was transformed into E. coli as described previously (Chung et al., 1989). E. coli S17-1 (Simon et al., 1983) was used to mobilize plasmids into P. pantotrophus GB17 according to Rother et al. (2001).

Site-directed mutagenesis. To establish the single amino acid exchanges Cys13Ala and Cys16Ala in SoxS, several cloning steps were required. (i) The hybridized oligonucleotides S50 5'-AATTCGGTACCGATATCCCCGGGG-3' and S51 5'-GATCCCCCGGGGATATCGGTACCG-3' introduced KpnI and SmaI restriction sites into the vector pGEM-11ZF + linearized with EcoRI and BamHI, resulting in plasmid pRD174.2. (ii) Plasmid pJOEB9 (Rother et al., 2005) harbouring soxR'SVWXYZABCDE' was restricted with $K p n \mathrm{I}$ and SmaI, yielding two fragments of $11081 \mathrm{bp}$ and $445 \mathrm{bp}$ in size. The 445 bp fragment with sox $S^{\prime}$ and sox $V^{\prime}$ was cloned into pRD174.2, yielding plasmid pRD175.2. This vector included the soxS region and was used for site-directed mutagenesis. Concomitantly with the selection oligonucleotide $5^{\prime}$-d(pCCGCGAGACCCACCCTTGGAGGCTCCAGATTTATC)-3' of the GeneEditor in vitro site-directed mutagenesis system, the oligonucleotides S52 5' -d(pCGAACAGCCCGGCGCCCTTTATTGCGCG)-3' for the Cys13Ala amino acid exchange and S53 5'-d(pCGGCTGCCTTTATGCCGCGCGCTGGGAC)-3' for the Cys16Ala amino acid exchange were hybridized with ssDNA of plasmid pRD175.2 at the same time. Mutations were verified by DNA sequencing of the relevant regions. The altered plasmids were designated pRD175.2mutS(C13A) and pRD175.2mutS(C16A). (iii) These plasmids were restricted with $K p n \mathrm{I}$ and SmaI. The $445 \mathrm{bp}$ mutated fragments were ligated with the KpnI-SmaI restricted vector pJOEB9, resulting in plasmids pRD176.1(C13A) and pRD177.28(C16A). The sequence was analysed to exclude the possibility of accidental restoration of the initial situation of vector pJOEB9. (iv) pRD176.1 and pRD177.28 were digested with HindIII. The $8911 \mathrm{bp}$ fragments with soxR'mutSVWXYZABCDE' were cloned in HindIII-restricted pVK101 (Knauf \& Nester, 1982) yielding pRD178.7 and pRD179.6. Both plasmids correspond to pVKB9 (Rother et al., 2001). The mutagenized sox genes were expressed in the homogenote strains $\mathrm{GB} \Omega \mathrm{S}$ (Rother et al., 2005) and GB $\Omega \mathrm{X}$ (Bardischewsky et al., 2005). 
Table 1. Bacterial strains and plasmids

\begin{tabular}{|c|c|c|}
\hline Strain or plasmid & Relevant genotype or phenotype ${ }^{\star}$ & Reference \\
\hline \multicolumn{3}{|l|}{ E. coli strains } \\
\hline JM109 & $\begin{array}{l}\text { recA1 supE44 endA1 hsdR17 gyrA96 relA1 thi } \Delta(\text { lac-proAB }) ; \mathrm{F}^{\prime}[\text { traD36 } \\
\left.\text { proAB }{ }^{+} \text {lacl }^{\mathrm{q}} \text { lacZ } \Delta \mathrm{M} 15\right]\end{array}$ & Yanisch-Perron et al. (1985) \\
\hline BMH 71-18 mutS & thi supE $\mathrm{D}($ lac-proAB), [mutS: $\operatorname{Tn} 10] \mathrm{F}^{\prime}\left[\right.$ proAB lacI ${ }^{q}$ lacZ $\left.\Delta \mathrm{M} 15\right]$ & $\begin{array}{l}\text { Kramer et al. (1984); Zell \& Fritz } \\
\text { (1987) }\end{array}$ \\
\hline S17-1 & recA pro thi hsdS, RP4-tra-functions supE44 & Simon et al. (1983) \\
\hline \multicolumn{3}{|l|}{ P. pantotrophus strains } \\
\hline GB17 & Sox $^{+}$ & $\begin{array}{l}\text { Rainey et al. (1999); Robertson \& } \\
\text { Kuenen (1983) }\end{array}$ \\
\hline $\mathrm{GB} \Omega \mathrm{S}$ & soxS: : $\Omega$ Sox $^{-}$ & Rother et al. (2005) \\
\hline $\mathrm{GB} \Omega \mathrm{X}$ & $\operatorname{sox} X:: \Omega S_{0 x}{ }^{-}$ & Bardischewsky et al. (2005) \\
\hline \multicolumn{3}{|l|}{ Plasmids } \\
\hline pGEM-11Zf $(+)$ & Cloning vector; $A m p^{\mathrm{r}}$, fl ori, lac $Z$ & Promega \\
\hline pJOEB9 & $\operatorname{sox} R^{\prime}-\operatorname{sox} E^{\prime}$ & Rother et al. (2005) \\
\hline pRD139.1 & pJOEB9 with a 3048 bp SstI deletion & This study \\
\hline pRD140.2 & 3048 bp SstI sox $Z^{\prime} A B C^{\prime}$ fragment in pUC19 & This study \\
\hline pRD140.2mutZ & pRD140.2 with Cys53Ser in sox $Z^{\prime}$ & This study \\
\hline pRD141.4 & 3048 bp SstI sox $Z^{\prime}$ mutABC fragment in pRD139.1 & This study \\
\hline pRD142.1 & $\begin{array}{l}8911 \text { bp HindIII fragment soxR'SVWXYZmutABCDE' from pJOEB9 } \\
\text { in pVK101 }\end{array}$ & This study \\
\hline pRD174.2 & Hybridized oligonucleotides S50/S51 in pGEM-11Zf $(+)$ & This study \\
\hline PRD175.2 & 445 bp KpnI-SmaI fragment of pJOEB9 in RD174.2 & This study \\
\hline pRD175.2mutS_C13A & pRD175.2 with C13A in soxS' & This study \\
\hline pRD175.2mutS_C16A & pRD175.2 with C16A in sox $S^{\prime}$ & This study \\
\hline pRD176.1 & 445 bp KpnI-SmaI fragment of $s o x S^{\prime}$ with C13A in pJOEB9 & This study \\
\hline pRD177.28 & 445 bp KpnI-SmaI fragment of $s o x S^{\prime}$ with C16A in pJOEB9 & This study \\
\hline pRD178.7 & 8911 bp HindIII fragment sox $R^{\prime}-s o x E^{\prime}$ with C13A in soxS in pVK101 & This study \\
\hline pRD179.6 & 8911 bp HindIII fragment soxR $R^{\prime}$ sox $E^{\prime}$ with $\mathrm{C} 16 \mathrm{~A}$ in soxS in pVK101 & This study \\
\hline pRD187.7 & 608 bp KpnI-BamHI fragment of soxS with C16A in pRI1 & This study \\
\hline pRI1 & $\mathrm{Cm}^{\mathrm{r}}, \mathrm{Sm}^{\mathrm{r}}$ & Pfitzner et al. (1998) \\
\hline pUC19 & $A p^{r}, l a c Z$ & Yanisch-Perron et al. (1985) \\
\hline pVK101 & $\mathrm{Km}^{\mathrm{r}}, \mathrm{Tc}^{\mathrm{r}}, \mathrm{Tra}^{-}, \mathrm{Mob}^{+}$ & Knauf \& Nester (1982) \\
\hline pVKB9 & 8851 bp HindIII fragment sox $R^{\prime}-$ sox $E^{\prime}$ in pVK101 & Rother et al. (2001) \\
\hline pVKB9C & $\begin{array}{l}8911 \text { bp HindIII fragment sox } R^{\prime} S V W X Y Z A B C D E^{\prime} \text { from pJOEB9 } \\
\text { in pVK101, in opposite orientation }\end{array}$ & This study \\
\hline
\end{tabular}

*Sox, lithotrophic growth with thiosulfate; Tra, transfer of mobilizable plasmids; Mob, mobilizability.

To establish a Cys53Ser exchange in SoxZ, four cloning steps were required. (i) Plasmid pJOEB9 was restricted with SstI, yielding two fragments, of 8478 and $3048 \mathrm{bp}$. The $8478 \mathrm{bp}$ fragment was religated after purification by elution from the gel, resulting in plasmid pRD139.1. (ii) The $3048 \mathrm{bp}$ fragment carrying the $\operatorname{sox} Z^{\prime} A B C^{\prime}$ genes was integrated into the linearized pUC19 vector (Yanisch-Perron et al., 1985), resulting in the $5734 \mathrm{bp}$ plasmid pRD140.2. This plasmid was used for site-directed mutagenesis of SoxZ. Concomitantly with the selection oligonucleotide $5^{\prime}$-d(CCGCGAGACCCACCCTTGGAGGCTCCAGATTTATC)-3', the oligonucleotide for the Cys53Ser exchange in SoxZ $5^{\prime}$-d(CACCCCGTTCAACTCCGAAGTGAAGCGGTTGATG)-3' was hybridized with ssDNA of plasmid pRD140.2. The altered plasmid was designated pRD140.2mut $Z$ and its correct sequence was verified. (iii) $\mathrm{pRD} 140.2 \mathrm{mut} Z$ was restricted with SstI. The 3048 bp fragment carrying the mutation in soxZ was ligated with the SstI-restricted vector pRD139.1, resulting in the 11526 bp plasmid pRD141.4. (iv) pRD141.4 was restricted with HindIII. The 8911 bp fragment with soxR'SVWXYZmutABCDE' was cloned in HindIII-restricted pVK101 (Knauf \& Nester, 1982), yielding pRD142.1. This plasmid corresponds to pVKB9C.

Cloning of soxS for expression in a soxY-free background. To identify possible unspecific SoxS adducts, the soxS gene was cloned for expression in a background lacking soxY expression. A $616 \mathrm{bp}$ soxS fragment containing soxS $(\mathrm{C} 16 \mathrm{~A})$ was isolated with the restriction enzymes KpnI and BamHI from plasmid pRD177.28. The resulting fragment was integrated into plasmid pRI1, resulting in plasmid pRD187.7 (Table 1). This plasmid was transformed into E. coli S17-1 and conjugated therefrom to strain $\mathrm{GB} \Omega \mathrm{X}$ and for reference into strain $\mathrm{GB} \Omega \mathrm{S}$.

Preparation of periplasmic extracts. Periplasmic extract was prepared by osmotic shock of the cells according to the method of Crowe \& Henco (1992). Cells from $200 \mathrm{ml}$ cultures (about $100 \mathrm{mg}$ protein) were harvested by centrifugation, washed once with $30 \mathrm{mM}$ Tris/ $\mathrm{HCl}, \mathrm{pH} 8.0$, and resuspended in $40 \mathrm{ml}$ of the same buffer 
containing $1 \mathrm{mM}$ EDTA and $20 \%$ (w/v) sucrose. Cells were stirred at room temperature for $10 \mathrm{~min}$, collected by centrifugation $(8000 \mathrm{~g}$, $4{ }^{\circ} \mathrm{C}$ ), and subjected to osmotic shock by resuspension and stirring $\left(10 \mathrm{~min}, 0{ }^{\circ} \mathrm{C}\right.$ ) in $40 \mathrm{ml} 5 \mathrm{mM} \mathrm{MgSO}$. The cells were collected as described above. The supernatant $(40 \mathrm{ml}, 10 \mathrm{mg}$ total protein) containing the osmotic shock fluid was stabilized by addition of Tris/ $\mathrm{HCl}, \mathrm{pH} 8.0$, to a final concentration of $30 \mathrm{mM}$ and of $1 \mu \mathrm{M}$ PMSF. Proteins were concentrated to $30-40 \mathrm{mg} \mathrm{ml}^{-1}$ using a cut-off of $10 \mathrm{kDa}$ (Amicon Ultra-15 Centrifugal Filter Device).

Purification of SoxS antigens. Periplasmic extract $(1 \mathrm{ml}, 38 \mathrm{mg}$ total protein) was subjected to Q-Sepharose chromatography (column diameter $1.6 \mathrm{~cm}$, height $3 \mathrm{~cm}$ ). Proteins were eluted in a step gradient of $0-0.40 \mathrm{M}$ sodium chloride with $0.05 \mathrm{M}$ intervals. Per step, $50 \mathrm{ml} 25 \mathrm{mM}$ BisTris/HCl buffer, $\mathrm{pH} 7.2$, including $1 \mathrm{mM}$ magnesium sulfate and $1 \mu \mathrm{M}$ PMSF, was collected in five fractions $(10 \mathrm{ml})$. SoxS antigens eluted at $0.20 \mathrm{M}$ sodium chloride, which was designated the SoxS fraction. Under these conditions SoxYZ antigens eluted predominantly at $0.15 \mathrm{M}$ sodium chloride.

Analytical prodedures. The thiosulfate-dependent oxygen uptake rate of whole cells was determined with an oxygen electrode (Rank Brothers). The assay $(3 \mathrm{ml})$ contained $50 \mu \mathrm{l}$ cell suspension $\left(\mathrm{OD}_{436}=30\right)$ equivalent to $150 \mu \mathrm{g}$ protein, and $100 \mu \mathrm{mol}$ sodium/ potassium phosphate buffer, $\mathrm{pH}$ 8.0. Reactions were started by addition of $30 \mu \mathrm{l} 0.20 \mathrm{M}$ sodium thiosulfate. One unit (U) of thiosulfate oxidation activity was defined as one micromole $\mathrm{O}_{2}$ consumed per minute. The specific activity was expressed as $\mathrm{U}$ (mg protein $)^{-1}$.

Thiosulfate was quantified according to Sørbø (1957).

Proteins were denatured and separated by SDS-PAGE according to Laemmli (1970). Proteins were stained with Coomassie blue as described by Weber et al. (1972). Immunoblot analysis (Towbin et al., 1979) was performed according to the 'semidry' procedure using the Multiphor electrophoretic system (Pharmacia) with polyclonal antibodies raised against SoxS and the SoxYZ complex.

To preserve protein disulfide bonds, samples were treated with SDS without 2-mercaptoethanol and without boiling. Proteins were separated by SDS-PAGE without 2-mercaptoethanol.

For in vitro SoxS adduct studies, homogeneous SoxYZ and SoxYZ(C53S) complexes were prepared and activated chemically prior to use according to Quentmeier et al. (2007).

\section{RESULTS}

\section{Site-directed mutagenesis of SoxS}

The absence of SoxS in strain GB $\Omega S$ can be chemically complemented by reduction of the cells with DTT, which recovers the thiosulfate oxidation rate (Orawski et al., 2007). Of the two reduced cysteine residues of the CysXaaXaaCys motif of thiol-disulfide oxidoreductases, one thiol binds to a disulfide of the target protein and forms an interprotein disulfide with the protein. The other thiol re-reduces this interprotein disulfide, releasing the target protein in the reduced state and the thiol-disulfide oxidoreductase in the oxidized state (Kadokura et al., 2003). To identify the crucial cysteine residue that covalently links the thiol-disulfide oxidoreductase with its periplasmic partner, each of the two active site cysteine residues of SoxS was exchanged for L-alanine by two independent mutageneses. The plasmids pRD178.7[C13A $]^{\mathrm{S}}$ and pRD179.6[C16A $]^{\mathrm{S}}$ carrying the respective mutations were conjugated into strain $\mathrm{GB} \Omega \mathrm{S}$. The resulting strains $\mathrm{GB} \Omega \mathrm{S}\left(\mathrm{pRD} 178.7[\mathrm{C} 13 \mathrm{~A}]^{\mathrm{S}}\right)$ and $\mathrm{GB} \Omega \mathrm{S}\left(\mathrm{pRD} 179.6[\mathrm{C} 16 \mathrm{~A}]^{\mathrm{S}}\right.$ ) were compared with $\mathrm{GB} \Omega \mathrm{S}$ (pVKB9) carrying the intact soxS gene in soxR'SVWXYZABCDE'.

Anti-SoxS antibodies identified SoxS antigens at a size of $11 \mathrm{kDa}$ in periplasmic extracts of the wild-type, the reference strain $\mathrm{GB} \Omega S$ (pVKB9), and in the two mutants with the Cys13Ala and Cys16Ala exchange in SoxS. SoxS antigens were absent in extracts of strain GB $\Omega$ S (Fig. 1). The level of soxS expression in the wild-type GB17 was slightly less than that of strain $\mathrm{GB} \Omega S$ (pVKB9) and the mutants derived therefrom due to the plasmid copy number (Fig. 1).

\section{Sox activity of strains with a $C_{13 A^{S}}$ or $\mathrm{C}_{16 A^{S}}$ mutation}

Under mixotrophic growth conditions thiosulfate-dependent oxygen uptake was started by the reference strain GB $\Omega S$ (pVKB9) after the consumption of the heterotrophic substrate succinate, and this rate was maintained at a high level over time. The SoxS-negative strain $G B \Omega S$ had only a low activity during transition from heterotrophic to chemotrophic metabolism, confirming previous results (Orawski et al., 2007). Such low activity was also observed for strain $\mathrm{GB} \Omega S\left(\mathrm{pRD} 179.6[\mathrm{C} 16 \mathrm{~A}]^{\mathrm{S}}\right.$ ) (Fig. 2). However, strain $\mathrm{GB} \Omega \mathrm{S}\left(\mathrm{pRD} 178.7[\mathrm{C} 13 \mathrm{~A}]^{\mathrm{S}}\right.$ ) transiently displayed about the same high activity as the reference strain GB $\Omega S$ (pVKB9), declining sharply in the early stationary phase, in which de novo protein synthesis ceases and reductant is no longer available (Fig. 2). This phenotypic difference between the two mutants indicated a functional difference between Cys13 and Cys16 of SoxS.

Under heterotrophic growth conditions only traces of thiosulfate-dependent oxygen uptake were observed for strain $\mathrm{GB} \Omega S$ s and $\mathrm{GB} \Omega \mathrm{S}\left(\mathrm{pRD} 179.6[\mathrm{C} 16 \mathrm{~A}]^{\mathrm{S}}\right)$. Again, strain $\mathrm{GB} \Omega \mathrm{S}\left(\mathrm{pRD} 178.7[\mathrm{C} 13 \mathrm{~A}]^{\mathrm{S}}\right.$ ) had about the same activity as strain $\mathrm{GB} \Omega \mathrm{S}$ (pVKB9) (data not shown), also suggesting a functional difference of the two cysteine residues.

Reduction of GB $\Omega S$ cells with DTT restores the thiosulfateoxidizing ability (Orawski et al., 2007). As expected,

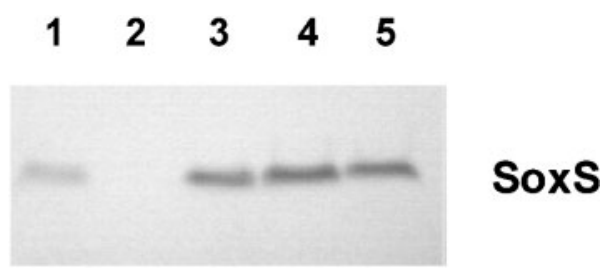

Fig. 1. Immunoblot analysis of SoxS antigens of periplasmic extracts. Lanes: 1, P. pantotrophus GB17; 2, GB $\Omega$; 3, GB $\Omega$ S $\left(p R D 178.7[\mathrm{C} 13 \mathrm{~A}]^{\mathrm{S}}\right) ; 4$, GB $\Omega S\left(\mathrm{pRD} 179.6[\mathrm{C} 16 \mathrm{~A}]^{\mathrm{S}}\right), 5, \mathrm{~GB} \Omega S$ (pVKB9). 


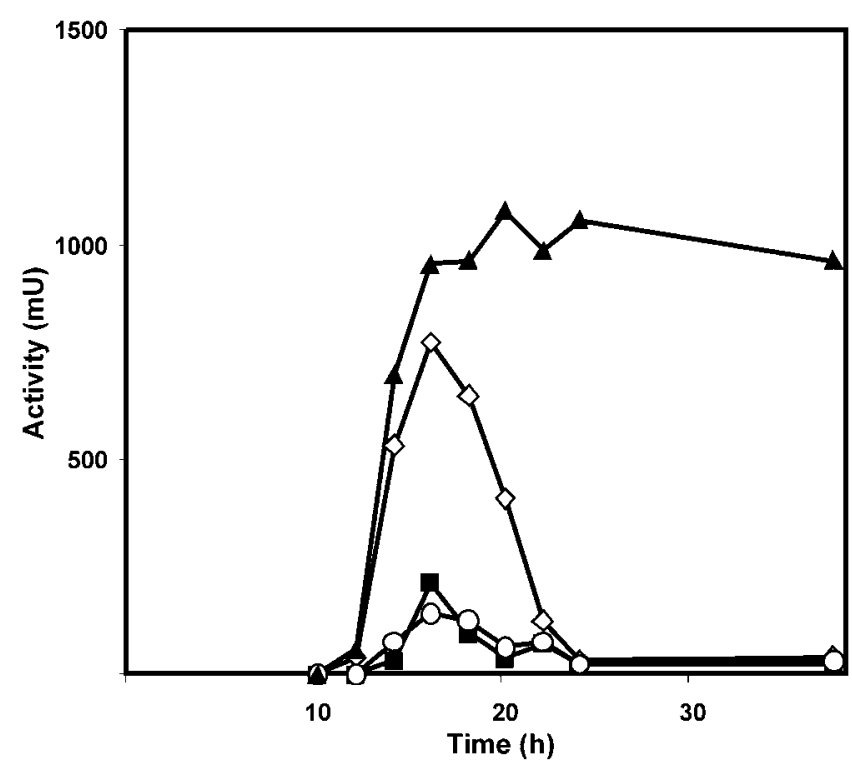

Fig. 2. Thiosulfate-dependent oxygen uptake rates of SoxS mutants of $P$. pantotrophus. Strains were cultivated mixotrophically with succinate plus thiosulfate. $\mathbf{\square}, \mathrm{GB} \Omega \mathrm{S} ; \diamond, \mathrm{GB} \Omega \mathrm{S}$ $\left(p R D 178.7[\mathrm{C} 13 \mathrm{~A}]^{\mathrm{S}}\right) ; \bigcirc, \mathrm{GB} \Omega \mathrm{S}\left(\mathrm{pRD} 179.6[\mathrm{C} 16 \mathrm{~A}]^{\mathrm{S}}\right) ; \boldsymbol{\Delta}, \mathrm{GB} \Omega \mathrm{S}$ (pVKB9).

addition of DTT to the medium at the end of the heterotrophic growth phase restored and stabilized the thiosulfate oxidation rate of strain GB $\Omega S$ $\left(\mathrm{pRD} 179.6[\mathrm{C} 16 \mathrm{~A}]^{\mathrm{S}}\right)$ to the same level as that of strain $\mathrm{GB} \Omega S$ (Fig. 3), confirming that the target of SoxS was chemically reduced.

In the stationary growth phase cells suffer from lack of reductant. Thus, these data suggested that the Sox system remained stable when reductant was available. In this sense the data were in accordance with the stably maintained activity under mixotrophic conditions, as sulfur metabolism supplies some reductant upon the onset of chemotrophic growth conditions.

\section{SoxS adduct detection by anti-SoxS antibodies}

Anti-SoxS antibodies identified SoxS antigens from periplasmic extracts of various mixotrophically cultivated $P$. pantotrophus strains. Expression of the soxS gene in the wild-type was low, and did not occur in strain GBSS. In the complemented GB $\Omega S$ strains, soxS expression was significantly higher (Fig. 4, lanes 3-5). A major band at $11 \mathrm{kDa}$ and a faint band at $25 \mathrm{kDa}$ were observed from the wild-type, strain $\mathrm{GB} \Omega S$ (pVKB9) and strain $\mathrm{GB} \Omega S\left(\mathrm{pRD} 178.7[\mathrm{C} 13 \mathrm{~A}]^{\mathrm{S}}\right)$. In contrast, in strain $\mathrm{GB} \Omega S$ $\left(\mathrm{pRD} 179.6[\mathrm{C} 16 \mathrm{~A}]^{\mathrm{S}}\right)$, a strong signal was present at $25 \mathrm{kDa}$ and a minor one at $11 \mathrm{kDa}$ (Fig. 4, lane 4). These results were in accordance with the physiological data and suggested that Cys13 of SoxS is the crucial residue for formation of a mixed disulfide. Since the mixed disulfide

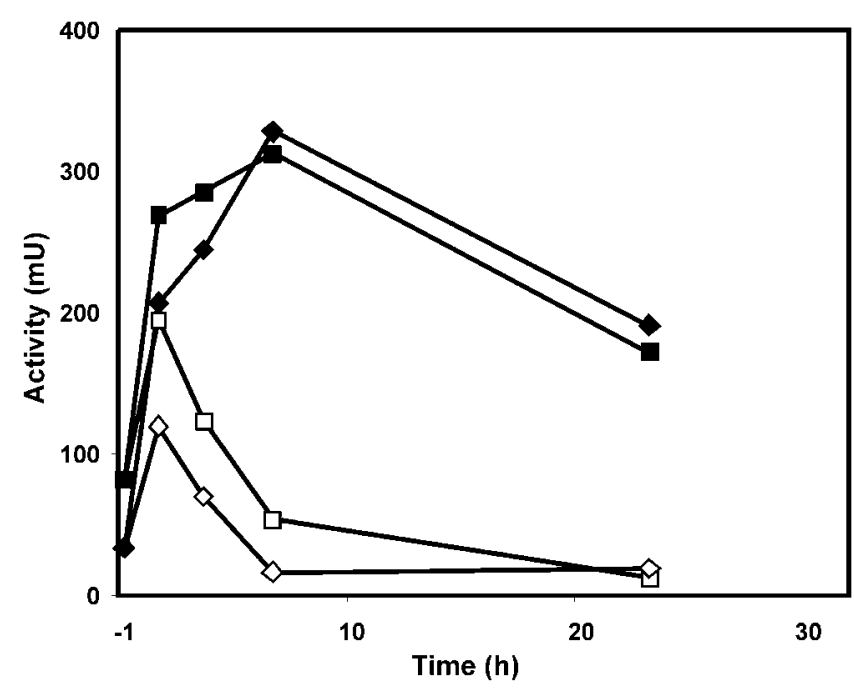

Fig. 3. Thiosulfate-dependent oxygen uptake rates of $P$. pantotrophus $\mathrm{GB} \Omega \mathrm{S}$ and $\mathrm{GB} \Omega \mathrm{S}\left(\mathrm{pRD} 176.9[\mathrm{C} 16 \mathrm{~A}]^{\mathrm{S}}\right.$ ). Both strains were cultivated mixotrophically with succinate plus thiosulfate. After reaching stationary growth phase the cultures were split; one portion of each strain was untreated; $\square, \mathrm{GB} \Omega S$; $\diamond, \mathrm{GB} \Omega S$ $\left(\mathrm{pRD} 179.6[\mathrm{C} 16 \mathrm{~A}]^{\mathrm{S}}\right)$; the other portion was treated with DTT (1 mM final concentration); $\mathbf{a}, \mathrm{GB} \Omega \mathrm{S} ; \quad \rightarrow \mathrm{GB} \Omega \mathrm{S}$ $\left(p R D 179.6[C 16 A]^{S}\right)$.

was most pronounced in extracts of strain $\mathrm{GB} \Omega S\left(\mathrm{pRD} 179.6[\mathrm{C} 16 \mathrm{~A}]^{\mathrm{S}}\right)$, this mutant was selected for further studies.

The size of the SoxS antigens (25 kDa, Fig. 5a, lane 1) did not exclude dimerization of SoxS (expected size $22 \mathrm{kDa}$ ). To examine accidental formation of SoxS dimers or adducts as a result of extract preparation, iodoacetamide,

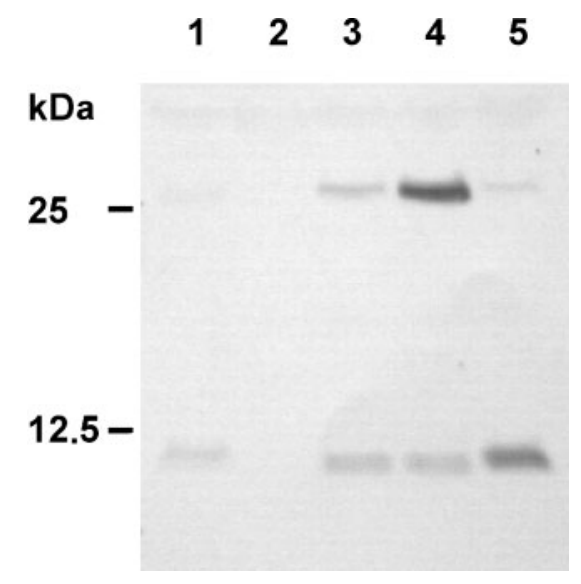

Fig. 4. Immunoblot analysis of periplasmic extracts separated by SDS-PAGE without 2-mercaptoethanol. Lanes: 1, P. pantotrophus $\mathrm{GB} 17 ; 2, \mathrm{~GB} \Omega \mathrm{S} ; 3$, GB $\Omega \mathrm{S}\left(\mathrm{pRD} 178.7[\mathrm{C} 13 \mathrm{~A}]^{\mathrm{S}}\right) ; 4$, GB $\Omega S$ $\left(p R D 179.6[\mathrm{C} 16 \mathrm{~A}]^{\mathrm{S}}\right) ; 5, \mathrm{~GB} \Omega \mathrm{S}(\mathrm{pVKB})$. 
(a)

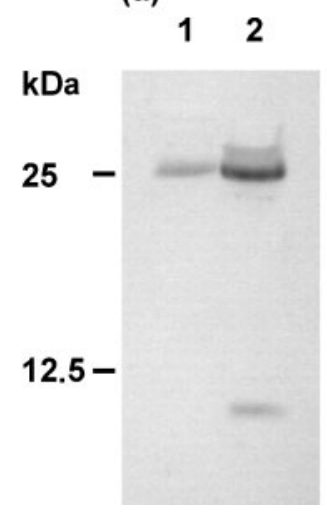

(b)

12

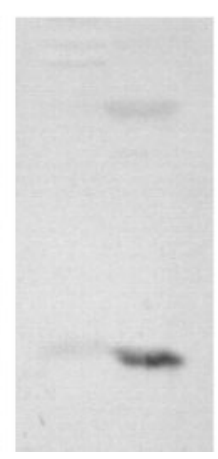

(c)

\section{$\begin{array}{lll}1 & 2 & 3\end{array}$}

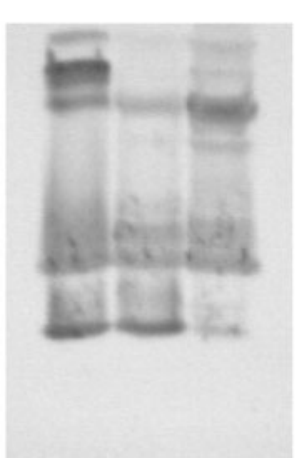

(d)

\section{$\begin{array}{lll}1 & 2 & 3\end{array}$}

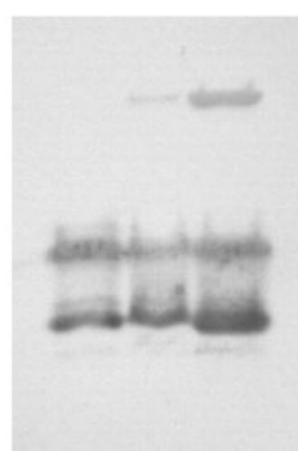

Fig. 5. Immunoblot analysis of periplasmic extracts and partially purified SoxS $[\mathrm{C} 16 \mathrm{~A}]^{\mathrm{S}}$. Mutated SoxS $[\mathrm{C} 16 \mathrm{~A}]^{\mathrm{S}}$ was purified by resource $\mathrm{Q}$ chromatography. Proteins (30 $\mu \mathrm{g}$ per well) were separated by SDS-PAGE without (a, c) and with 2mercaptoethanol (b, d). SoxS was identified by anti-SoxS antibodies ( $a, b)$, and SoxYZ by anti-SoxYZ antibodies (c, d). Lanes $(a, b): 1$, periplasmic extract of $\mathrm{GB} \Omega S\left(p R D 179.6[C 16 A]^{S}\right) ; 2$, purified SoxS $(C 16 A)(30 \mu \mathrm{g}$ protein per well). Lanes (c, d): 1, $1.2 \mu \mathrm{g}$ homogeneous SoxYZ 'as isolated'; 2, periplasmic extract of GB $\Omega S$ (pRD179.6[C16A $]^{S}$ ); 3, purified SoxS(C16A).

a chemical that traps free thiols, was added to cells of strain $\mathrm{GB} \Omega S\left(\mathrm{pRD} 179.6[\mathrm{C} 16 \mathrm{~A}]^{\mathrm{S}}\right)$. However, no difference in size $(25 \mathrm{kDa})$ or intensity was observed from immunoblots of extracts of this strain, indicating that the $25 \mathrm{kDa}$ complex was not an artefact (data not shown). Moreover, treatment of SoxS with $10 \mathrm{mM}$ hydrogen peroxide did not alter the size from $11 \mathrm{kDa}$ (data not shown).

Chromatography of extracts of strain GB $\Omega S(p R D 179.6$ $[\mathrm{C} 16 \mathrm{~A}]^{\mathrm{S}}$ ) on Q-Sepharose eluted SoxS antigens in the SoxS fraction at $0.20 \mathrm{M}$ sodium chloride. From SDS-PAGE without reductant, anti-SoxS antibodies identified a major band at $25 \mathrm{kDa}$ and minor bands at 26 and $11 \mathrm{kDa}$ (Fig. 5a, lane 2). The minor signal at $11 \mathrm{kDa}$ indicated that the adduct of about $14 \mathrm{kDa}$ was split off to release SoxS. The minor signal at $26 \mathrm{kDa}$ was not identified, and may represent an adduct whose interprotein disulfide was not solvent-accessible, or a situation in which SoxS was linked by a thioether bond that was not split upon reduction by 2 mercaptoethanol (see also Fig. 5b, lane 2).

\section{SoxY adduct detection by anti-SoxYZ antibodies}

Polyclonal anti-SoxYZ antibodies specific for SoxYZ antigens were used to identify SoxS adducts from periplasmic extracts of mixotrophically grown strain $\mathrm{GB} \Omega S\left(\mathrm{pRD} 179.6[\mathrm{C} 16 \mathrm{~A}]^{\mathrm{S}}\right)$. SDS-PAGE separated intense bands corresponding to SoxY (10977 Da) and SoxZ $(11017 \mathrm{Da})$, and migrating at 12 and $16 \mathrm{kDa}$, respectively (Rother et al., 2001). The $26 \mathrm{kDa}$ band observed from the SoxS fraction of Q-Sepharose chromatography (Fig. 5c) was also present in purified SoxS preparations in which SoxS antigens were identified by anti-SoxS antibodies (Fig. 5a, lane 2).

From SDS-PAGE without 2-mercaptoethanol, anti-SoxYZ antibodies identified SoxYZ antigens from homogeneous
SoxYZ at 12, 16, 25, 29 and $32 \mathrm{kDa}$ (Fig. 5c, lane 1). These signals represented the SoxY and SoxZ monomers and the SoxY-Y, SoxY-Z and SoxZ-Z dimers (Quentmeier et al., 2003, 2007). From periplasmic extract of strain $\mathrm{GB} \Omega S\left(\mathrm{pRD} 179.6[\mathrm{C} 16 \mathrm{~A}]^{\mathrm{S}}\right.$ ), signals at 12,16 and $25 \mathrm{kDa}$ were present (Fig. 5c, lane 2). From the Q-Sepharose SoxS fraction a major band of $25 \mathrm{kDa}$ and traces of the size of SoxY were observed (Fig. $5 c$, lane 3 ). The size of the SoxY$\mathrm{Y}$ dimer was identical with that of the SoxS adduct. However, SoxS antigens were identified by anti-SoxS antibodies from Q-Sepharose chromatography and these reacted with specific anti-SoxYZ antibodies (Fig. 5c, lane 3 ). This result argued against dimerization of either SoxS or the SoxYZ subunits. Also, a dimeric SoxS would be expected to migrate at $22 \mathrm{kDa}$, while the dimers of SoxY and SoxZ migrate at 25, 29 and $32 \mathrm{kDa}$ (Fig. 5c, lane 1; Quentmeier et al., 2007). Thus, these experiments suggested that SoxY is the adduct of SoxS. To verify the antibody signals at $25 \mathrm{kDa}$, SoxS adduct formation was examined in strains unable to produce SoxYZ.

\section{SoxS(C16A) adduct formation in vivo requires SoxYZ}

Strain GB $\Omega \mathrm{X}$ is unable to express the soxXYZA-H genes (Bardischewsky et al., 2005), while these genes are well expressed in strain GB $\Omega S$ (Orawski et al., 2007). Both strains were used as background to produce SoxS and to examine adduct formation. As expected, SDS-PAGE of periplasmic extracts of strain $\mathrm{GB} \Omega S\left(\mathrm{pRD} 187.7[\mathrm{C} 16 \mathrm{~A}]^{\mathrm{S}}\right.$ ) and SDS-PAGE with reductant of strain $\mathrm{GB} \Omega \mathrm{X}\left(\mathrm{pRD} 187.7[\mathrm{C} 16 \mathrm{~A}]^{\mathrm{S}} \text { ) identified SoxS[C16A }\right]^{\mathrm{S}}$ antigens at $11 \mathrm{kDa}$ (Fig. 6a). However, without reductant, formation of an adduct to SoxS with a mobility equivalent to $25 \mathrm{kDa}$ was observed exclusively from strain $\mathrm{GB} \Omega S\left(\mathrm{pRD} 187.7[\mathrm{C} 16 \mathrm{~A}]^{\mathrm{S}}\right)$ and not from strain 
(a)

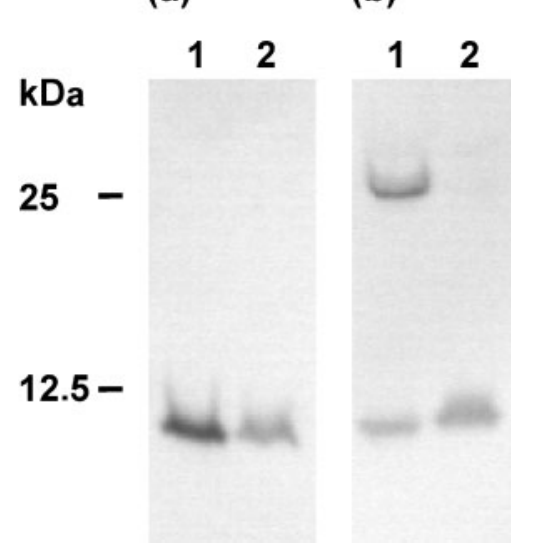

Fig. 6. Immunoblot analysis of SoxS antigens in a SoxYZ-free strain. Periplasmic extracts of $\mathrm{GB} \Omega \mathrm{S}\left(\mathrm{pRD} 187.7[\mathrm{C} 16 \mathrm{~A}]^{\mathrm{S}}\right.$ ) (lanes 1) and $\mathrm{GB} \Omega \mathrm{X}\left(\mathrm{pRD} 187.7[\mathrm{C} 16 \mathrm{~A}]^{\mathrm{S}}\right)$ unable to produce SoxYZ (lanes 2) were separated by SDS-PAGE with (a) and without (b) 2mercaptoethanol and with antibodies against SoxS (30 $\mu$ g protein per well).

GB $\Omega X\left(p R D 187.7[C 16 A]^{\mathrm{S}}\right.$ ) (Fig. 6b). This result suggested that SoxS was linked to a protein with a mobility equivalent to a size of about $14 \mathrm{kDa}$. The size of $25 \mathrm{kDa}$ differed noticeably from $22 \mathrm{kDa}$, the mass of a SoxS dimer. Therefore, such dimer formation was not considered. The fact that no SoxS adduct was observed from the

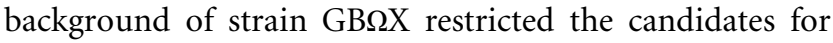
adduct formation to the Sox proteins encoded by the transcriptional unit soxX-H. However, of these Sox proteins, none has the appropriate size or mobility, except SoxY and SoxZ (Rother et al., 2001). Therefore, in vitro studies were performed to distinguish the two possibilities for adduct formation.

\section{SoxS(C16A)-SoxY adduct formation in vitro}

Periplasmic extract of strain GB $\Omega X\left(p R D 187.7[\mathrm{C} 16 \mathrm{~A}]^{\mathrm{S}}\right)$ did not contain SoxS antigens of a molecular mass of $25 \mathrm{kDa}$ (Figs 6b, lane 2, and 7, lane 2). However, when this extract was mixed and incubated with homogeneous SoxYZ 'as isolated', SoxS antigens were observed at $25 \mathrm{kDa}$. Sodium sulfide $(10 \mathrm{mM})$ activates SoxYZ 'as isolated' and causes a change in conformation (Quentmeier et al., 2007). Therefore, SoxS adduct formation was examined with SoxYZ 'activated'. No difference in intensity of the $25 \mathrm{kDa}$ adduct band was observed (Fig. 7, lanes 3 and 4).

SoxY migrates in SDS-PAGE at $12 \mathrm{kDa}$ and SoxZ at $16 \mathrm{kDa}$, and both SoxY and SoxZ contain a single cysteine residue (Friedrich et al., 2000). The size difference of $14 \mathrm{kDa}$ for the adduct suggested SoxY but did not allow unequivocal differentiation between the two subunits as adducts. Therefore, SoxZ was subjected to site-directed mutagenesis to generate the exchange Cys53Ser. The

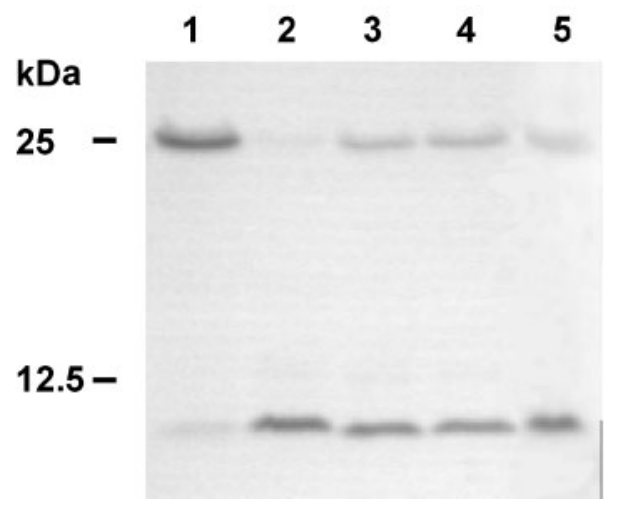

Fig. 7. Complementation of extracts of strain $\mathrm{GB} \Omega \mathrm{X}$ $\left(p R D 187.7[C 16 A]^{S}\right)$ with purified SoxYZ and SoxYZ(C53S). Periplasmic extracts of $\mathrm{GB} \Omega \mathrm{X}\left(\mathrm{pRD} 187.7[\mathrm{C} 16 \mathrm{~A}]^{\mathrm{S}}\right)$ were separated by SDS-PAGE without 2-mercaptoethanol. SoxS antigens were identified by immunoblot analysis with antibodies against SoxS on a native gel $(30 \mu \mathrm{g}$ protein per well). Lanes: $1, \mathrm{~GB} \Omega S$ $\left(p R D 187.7[\mathrm{C} 16 \mathrm{~A}]^{\mathrm{S}}\right) ; 2, \mathrm{~GB} \Omega \mathrm{X}\left(\mathrm{pRD} 187.7[\mathrm{C} 16 \mathrm{~A}]^{\mathrm{S}}\right) ; 3, \mathrm{~GB} \Omega \mathrm{X}$ $\left(\mathrm{pRD} 187.7[\mathrm{C} 16 \mathrm{~A}]^{\mathrm{S}}\right)+0.8 \mu \mathrm{g}$ SoxYZ 'as isolated'; 4, GB $\Omega \mathrm{X}$ $\left(\mathrm{pRD} 187.7[\mathrm{C} 16 \mathrm{~A}]^{\mathrm{S}}\right)+0.8 \mu \mathrm{g}$ activated SoxYZ; 5, GB $\Omega X$ $\left(p R D 187.7[C 16 A]^{S}\right)+0.8 \mu g$ SoxYZ(C53S).

cysteine residue in SoxZ is not conserved in sulfuroxidizing bacteria (Friedrich et al., 2008).

As expected, strain GB $\Omega$ X (pRD140.2[C53S $]^{\mathrm{Z}}$ ) grew with thiosulfate as the wild-type did. Also, in the reconstituted enzyme system homogeneous SoxYZ(C53S) had identical activity to that of SoxYZ (data not shown). Therefore, SoxYZ(C53S) was used to complement extracts of strain $\mathrm{GB} \Omega \mathrm{X}\left(\mathrm{pRD} 187.7[\mathrm{C} 16 \mathrm{~A}]^{\mathrm{S}}\right)$. This complementation revealed an identical adduct formation of $25 \mathrm{kDa}$ to SoxS(C16A) (Fig. 7, lane 5). These data demonstrated that SoxY was specifically linked to SoxS via an interprotein disulfide.

\section{DISCUSSION}

The thiol-disulfide oxidoreductase SoxS of $P$. pantotrophus is essential for keeping the Sox enzyme system in the active state, but SoxS does not participate in the sulfur-oxidizing reaction (Orawski et al., 2007). This observation led to the search for the periplasmic target of SoxS. To trap the target we applied site-directed mutagenesis of the active site cysteine residues of SoxS. We here present cumulative evidence that the SoxY subunit of the SoxYZ complex is the specific target of SoxS.

First, site-directed mutagenesis identified $\mathrm{C} 13^{\mathrm{S}}$ as not being crucial for sulfur oxidation in vivo but beneficial for maintaining a high sulfur oxidation rate, while $\mathrm{C} 16^{\mathrm{S}}$ was essential. The lack of the thiol in SoxS $(\mathrm{C} 16 \mathrm{~A})$ made the interaction abortive with respect to catalytic turnover, suggesting that $\mathrm{C}_{13} \mathrm{~S}$ forms a disulfide link with the periplasmic partner of SoxS (Fig. 8). Second, anti-SoxS 
(a)

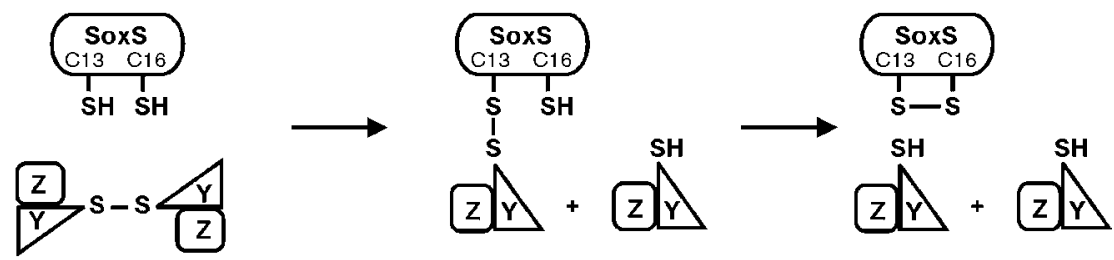

(b)

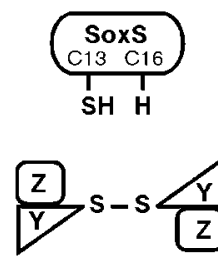

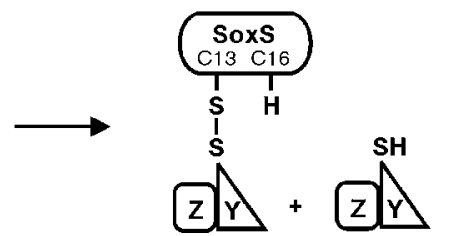

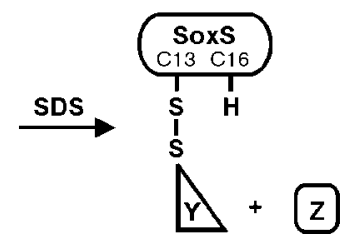

Fig. 8. Model of disulfide reduction by the thiol-disulfide oxidoreductase SoxS (a) and mixed disulfide formation of SoxS(C16A) with SoxY (b).

antibodies detected the $11 \mathrm{kDa}$ SoxS at $25 \mathrm{kDa}$ in periplasmic extracts. Reduction abolished the $25 \mathrm{kDa}$ species, which identified the $25 \mathrm{kDa}$ molecule as a mixed disulfide with a partner of about $14 \mathrm{kDa}$. Also, an intense $25 \mathrm{kDa}$ signal was detected with anti-SoxYZ antibodies, which however coincided with the size of a SoxY-Y homodimer. Third, immunoblot analysis identified the $25 \mathrm{kDa}$ protein as an adduct of a Sox protein to SoxS(C16A), as a molecule of this size was absent from cells unable to express the SoxXYZA-H genes. Of the Sox proteins, only SoxY exhibited a mobility equivalent to a size of $\sim 14 \mathrm{kDa}$. Fourth, the $25 \mathrm{kDa}$ SoxS(C16A) adduct was detected with anti-SoxS antibodies when homogeneous SoxYZ was added to extracts of a strain unable to produce SoxYZ. Finally, the $25 \mathrm{kDa}$ adduct was also obtained when homogeneous SoxYZ(C53S) was mixed with extracts containing SoxS(C16A), which excluded SoxZ as adduct.

The active site of SoxYZ is Cys110, located at the carboxy terminus on a peptide swinging arm which facilitates the access of the sulfur substrate to the thiol and its oxidative link (Sauvé et al., 2007; Quentmeier \& Friedrich, 2001). This structural characteristic, however, also facilitates interprotein disulfide formation. As a consequence, two SoxY subunits are covalently bound via their Cys110 residues (Quentmeier et al., 2007) to yield SoxY-Y, as also observed for the SoxY subunit of Chlorobium limicola (Stout et al., 2007). Exposure of the active site thiol results in an interprotein disulfide bond between the SoxY subunits and yields the SoxY-Y $(\mathrm{Z})_{2}$ heterotetramer. Also, low-molecular-mass compounds that react with free thiols bind to SoxY (Quentmeier et al., 2003). Consequently, oxidation of the Cys110 thiol other than by the linkage of a sulfur substrate inactivates SoxYZ and eliminates the protein from the chemotrophic sulfur-oxidizing reaction, and this results in a drastically (80\%) decreased sulfuroxidizing activity in vivo as observed for strain $G B \Omega S$ (Orawski et al., 2007).
The thioredoxin SoxW is reduced by the cysteine disulfide transporter SoxV (Bardischewsky et al., 2006). Very likely, SoxS is also reduced by SoxV. The $25 \mathrm{kDa}$ SoxS(C16A) adduct was identified by anti-SoxS antibodies. This adduct was exclusively observed either when SoxYZ was formed by the cells or when SoxYZ was added to periplasmic extracts of the SoxS(C16A) mutant. Therefore, the reduction of SoxS can be regarded as a salvage reaction for reintegration of accidentally oxidized SoxY species into the reaction cycle for chemotrophic sulfur oxidation.

\section{ACKNOWLEDGEMENTS}

The financial support of this study from the Deutsche Forschungsgemeinschaft to C. G. F. (grant no. Fr 318/9-2) is gratefully acknowledged.

\section{REFERENCES}

Bamford, V. A., Bruno, S., Rasmussen, T., Appia-Ayme, C., Cheesman, M. R., Berks, B. C. \& Hemmings, A. M. (2002). Structural basis for the oxidation of thiosulfate by a sulfur cycle enzyme. EMBO J 21, 5599-5610.

Bardischewsky, F. \& Friedrich, C. G. (2001a). Identification of $c c d A$ in Paracoccus pantotrophus GB17: disruption of $c c d A$ causes complete deficiency in $c$-type cytochromes. J Bacteriol 183, 257-263.

Bardischewsky, F. \& Friedrich, C. G. (2001b). The shxVW locus is essential for oxidation of inorganic sulfur and molecular hydrogen by Paracoccus pantotrophus GB17: a novel function in lithotrophy. FEMS Microbiol Lett 202, 215-220.

Bardischewsky, F., Quentmeier, A., Rother, D., Hellwig, P., Kostka, S. \& Friedrich, C. G. (2005). Sulfur dehydrogenase of Paracoccus pantotrophus: the heme-2 domain of the molybdoprotein cytochrome $c$ complex is dispensable for catalytic activity. Biochemistry 44, 7024-7034.

Bardischewsky, F., Fischer, J., Höller, B. \& Friedrich, C. G. (2006). SoxV transfers electrons to the periplasm of Paracoccus pantotrophusan essential reaction for chemotrophic sulfur oxidation. Microbiology $152,465-472$. 
Chung, C. T., Niemela, S. L. \& Miller, R. H. (1989). One-step preparation of competent Escherichia coli: transformation and storage of bacterial cells in the same solution. Proc Natl Acad Sci U S A 86, 2172-2175.

Crowe, J. \& Henco, K. (1992). The QIAexpressionist, 2nd edn. Chatsworth, CA: Qiagen

Friedrich, C. G., Quentmeier, A., Bardischewsky, F., Rother, D., Kraft, R., Kostka, S. \& Prinz, H. (2000). Novel genes coding for lithotrophic sulfur oxidation of Paracoccus pantotrophus GB17. J Bacteriol 182, 4677-4687.

Friedrich, C. G., Rother, D., Bardischewsky, F., Quentmeier, A. \& Fischer, J. (2001). Oxidation of reduced inorganic sulfur compounds by bacteria: emergence of a common mechanism? Appl Environ Microbiol 67, 2873-2882.

Friedrich, C. G., Bardischewsky, F., Rother, D., Quentmeier, A. \& Fischer, J. (2005). Prokaryotic sulfur oxidation. Curr Opin Microbiol 8, 253-259.

Friedrich, C. G., Quentmeier, A., Bardischewsky, F., Rother, D., Orawski, G., Hellwig, P. \& Fischer, J. (2008). Redox control of chemotrophic sulfur oxidation of Paracoccus pantotrophus. In Microbial Sulfur Metabolism, pp. 139-150. Edited by C. Dahl \& C. G. Friedrich. Berlin: Springer Verlag.

Kadokura, H., Katzen, F. \& Beckwith, J. (2003). Protein disulfide bond formation in prokaryotes. Annu Rev Biochem 72, 111-135.

Kelly, D. P., Shergill, J. K., Lu, W.-P. \& Wood, A. P. (1997). Oxidative metabolism of inorganic sulfur compounds by bacteria. Antonie Van Leeuwenhoek 71, 95-107.

Kieser, T. (1984). Factors affecting the isolation of CCC DNA from Streptomyces lividans and Escherichia coli. Plasmid 12, 19-36.

Kishigami, S., Kanaya, E., Kikuchi, M. \& Ito, K. (1995). DsbA-DsbB interaction through their active site cysteines. Evidence from an odd cysteine mutant of DsbA. J Biol Chem 270, 17072-17074.

Knauf, V. C. \& Nester, E. W. (1982). Wide host range cloning vectors: a cosmid clone bank of an Agrobacterium Ti plasmid. Plasmid 8, 45-54.

Kramer, B., Kramer, W. \& Fritz, H. J. (1984). Different base/base mismatches are corrected with different efficiencies by the methyldirected DNA mismatch-repair system of E. coli. Cell 38, 879-887.

Laemmli, U. K. (1970). Cleavage of structural proteins during the assembly of the head of bacteriophage T4. Nature 227, 680-685.

Linke, K. \& Jakob, U. (2003). Not every disulfide lasts forever: disulfide bond formation as a redox switch. Antioxid Redox Signal $\mathbf{5}$, 425-434.

Ludwig, W., Mittenhuber, G. \& Friedrich, C. G. (1993). Transfer of Thiosphaera pantotropha to Paracoccus denitrificans. Int J Syst Bacteriol 43, 363-367.

Nakamoto, H. \& Bardwell, J. C. (2004). Catalysis of disulfide bond formation and isomerization in the Escherichia coli periplasm. Biochim Biophys Acta 1694, 111-119.

Orawski, G., Bardischewsky, F., Quentmeier, A., Rother, D. \& Friedrich, C. G. (2007). The periplasmic thioredoxin SoxS plays a key role in activation in vivo of chemotrophic sulfur oxidation of Paracoccus pantotrophus. Microbiology 153, 1081-1086.

Pfitzner, U., Odenwald, A., Ostermann, T., Weingard, L., Ludwig, B. \& Richter, O. M. (1998). Cytochrome $c$ oxidase (heme $a a_{3}$ ) from Paracoccus denitrificans: analysis of mutations in putative proton channels of subunit I. J Bioenerg Biomembr 30, 89-97.

Quentmeier, A. \& Friedrich, C. G. (2001). The cysteine residue of the SoxY protein as the active site of protein-bound sulfur oxidation of Paracoccus pantotrophus GB17. FEBS Lett 503, 168-172.
Quentmeier, A., Hellwig, P., Bardischewsky, F., Grelle, G., Kraft, R. \& Friedrich, C. G. (2003). Sulfur oxidation in Paracoccus pantotrophus: interaction of the sulfur-binding protein SoxYZ with the dimanganese SoxB protein. Biochem Biophys Res Commun 312, 1011-1018.

Quentmeier, A., Janning, P., Hellwig, P. \& Friedrich, C. G. (2007). Activation of the heterodimeric central complex SoxYZ of chemotrophic sulfur oxidation is linked to a conformational change and SoxYY interprotein disulfide formation. Biochemistry 46, 10990-10998.

Rainey, F. A., Kelly, D. P., Stackebrandt, E., Burghardt, J., Hiraishi, A., Katayama, Y. \& Wood, A. P. (1999). A re-evaluation of the taxonomy of Paracoccus denitrificans and a proposal for the combination Paracoccus pantotrophus comb. nov. Int J Syst Bacteriol 49, 645-651.

Ritz, D. \& Beckwith, J. (2002). Redox state of cytoplasmic thioredoxin. Methods Enzymol 347, 360-370.

Robertson, L. A. \& Kuenen, J. G. (1983). Thiosphaera pantotropha gen. nov. sp. nov., a facultatively anaerobic, facultative autotrophic sulphur bacterium. J Gen Microbiol 129, 2847-2855.

Rother, D., Henrich, H.-J., Quentmeier, A., Bardischewsky, F. \& Friedrich, C. G. (2001). Novel genes of the sox gene cluster, mutagenesis of the flavoprotein SoxF, and evidence for a general sulfur oxidizing system in Paracoccus pantotrophus GB17. J Bacteriol 183, 4499-4508.

Rother, D., Orawski, G., Bardischewsky, F. \& Friedrich, C. G. (2005). SoxRS-mediated regulation of chemotrophic sulfur oxidation in Paracoccus pantotrophus. Microbiology 151, 1707-1716.

Sambrook, J., Fritsch, E. F. \& Maniatis, T. (1989). Molecular Cloning: a Laboratory Manual, 2nd edn. Cold Spring Harbor, NY: Cold Spring Harbor Laboratory.

Sanger, F., Nicklen, S. \& Coulson, A. R. (1977). DNA sequencing with chain-terminating inhibitors. Proc Natl Acad Sci U S A 74, 5463-5467.

Sauvé, V., Bruno, S., Berks, B. C. \& Hemmings, A. M. (2007). The SoxYZ complex carries sulfur cycle intermediates on a peptide swinging arm. J Biol Chem 282, 23194-23204.

Simon, R., Priefer, U. \& Pühler, A. (1983). A broad host range mobilization system for in vivo genetic engineering: transposon mutagenesis in Gram negative bacteria. Bio/Technology 1, 784-790.

Sørbø, B. (1957). A colorimetric method for the determination of thiosulfate. Biochim Biophys Acta 23, 412-416.

Stout, J., Van Driessche, G., Savvides, S. N. \& Van Beeumen, J. (2007). X-ray crystallographic analysis of the sulfur carrier protein SoxY from Chlorobium limicola f. thiosulfatophilum reveals a tetrameric structure. Protein Sci 16, 589-601.

Tapley, T. L., Eichner, T., Gleiter, S., Ballou, D. P. \& Bardwell, J. C. A. (2007). Kinetic characterization of the disulfide bond-forming enzyme DsbB. J Biol Chem 282, 10263-10271.

Thöny-Meyer, L. (1997). Biogenesis of respiratory cytochromes in bacteria. Microbiol Mol Biol Rev 61, 337-376.

Towbin, H., Staehelin, T. \& Gordon, J. (1979). Electrophoretic transfer of proteins from polyacrylamide gels to nitrocellulose sheets: procedure and some applications. Proc Natl Acad Sci U S A 76, 4350-4354.

Weber, K., Pringle, J. R. \& Osborn, M. (1972). Measurement of molecular weights by electrophoresis on SDS polyacrylamide gel. Methods Enzymol 26, 3-27.

Yanisch-Perron, C., Vieira, J. \& Messing, J. (1985). Improved M13 phage cloning vectors and host strains: nucleotide sequences of the M13mp18 and pUC19 vectors. Gene 33, 103-119.

Zell, R. \& Fritz, H. J. (1987). DNA mismatch-repair in Escherichia coli counteracting the hydrolytic deamination of 5-methyl-cytosine residues. EMBO J 6, 1809-1815.

Edited by: R. J. M. van Spanning 